\title{
Task Scheduler of Sending Electronic Mails Automatically
}

\author{
P Geetha, M Thamizharasi, R Reni Hena Helan, G Abirami, G Kalaiarasi
}

\begin{abstract}
Nowadays, Every one of every shop, each provisional stores, banking, marketing, etc., everywhere using app to send the any details of each customer should view the message or email alerts. In Earlier days, we used Microsoft Outlook to send and receive emails automatically with limited users of online mode communication. In this paper, scheduler logic will follow to read a data from excel database and used an authenticated email with less secure of SMTP properties that should match with system date. Then, Using Task Scheduler of creating a basic task with a batch file it will send an email automatically. Using any IDE of supports maven properties and setting up a database of scheduler logic was used and batch file of Jar File was created that must be fed into the task scheduler of source link. Finally, Based on System's Date $(\mathrm{mm} / \mathrm{dd})$ get the data from excel database and the task of sending emails to be send appropriate users automatically.
\end{abstract}

Key words : Task Scheduling, Database Scheduling, SMTP

\section{INTRODUCTION}

Our Task/Scheduler Logic (TSL) is intended to permit measured portrayal of the simultaneousness situations that regularly happen in frameworks programming. We start with a basic model of simultaneous frameworks that comprise of a uniprocessor scheduler, a lot of assignments, and a lot of assets got to by those errands. Undertakings are streams of control through segments; as a rule an assignment is expressly conjured by a scheduler that is executed either in equipment (e.g., an intrude on controller) or programming (e.g., a conventional string scheduler). All undertakings have an all around characterized passage point and most assignments additionally finish. A few errands exemplify a boundless circle and these never finish.

Task Scheduler is a segment of Microsoft Windows that gives the capacity to plan the dispatch of projects or contents

Revised Manuscript Received on April 17, 2020.

* Correspondence Author

P Geetha*, Department of CSE, Dhanalakshmi College of Engineering, Tambaram, India. Email:geetha_mails@yahoo.com

G Kalaiarasi, Department of CSE, SRM Institute of Science and Technology, Scholinganallur, India. Email:kalaikannan.l@gmail.com

M Thamizharasi, Department of CSE, Dhanalakshmi College of Engineering, Tambaram, India. Email:m.thamizharasi@gmail.com

R Reni hena helan, Department of CSE, Dhanalakshmi College of Engineering, Tambaram, India. Email:renihenahelan@gmail.com

G Abirami, Department of CSE, Dhanalakshmi College of Engineering, Tambaram, India. Email:gabirami08@gmail.com

G Kalaiarasi, Department of CSE, Sathyabama Institute of Science and Technology,Email:kalaikannan.l@gmail.com

(c) The Authors. Published by Blue Eyes Intelligence Engineering and Sciences Publication (BEIESP). This is an open access article under the CC BY-NC-ND license (http://creativecommons.org/licenses/by-nc-nd/4.0/) at pre-characterized times or after indicated time interims: work booking (task scheduling).Task Scheduler 2.0 was presented with Windows Vista and remembered for Windows Server 2008 as well.[2] The overhauled Task Scheduler UI is currently founded on Management Console. Notwithstanding running undertakings on planned occasions or indicated interims, Task Scheduler 2.0 likewise bolsters schedule and occasion based triggers, for example, beginning an assignment when a specific occasion is logged to the occasion log, or when a mix of occasions has happened. Additionally, a few undertakings that are activated by a similar occasion can be arranged to run either at the same time or in a pre-decided tied grouping of a progression of activities, rather than making various planned errands. Undertakings can likewise be arranged to run dependent on framework status, for example, being inactive for a pre-designed measure of time, on startup, logoff, or just during or for a predefined time.

Simple Mail Transfer Protocol, a convention for sending email messages between servers. Most email frameworks that send letters over the Internet use SMTP to send messages starting with one server then onto the next; the messages would then be able to be recovered with an email customer utilizing either POP or IMAP. Likewise, SMTP is commonly used to send messages from a mail customer to a mail server. This is the reason you have to indicate both the POP or IMAP server and the SMTP server when you arrange your email application.

\section{REVIEW STUDY}

1. Microsoft Outlook online suite of webmail, contacts, errands, and calendaring administrations from Microsoft. Naturally interface with Office Online and alter records one next to the other in email, consistently progress among talk and email with Skype, and offer connections from the cloud with OneDrive. Microsoft Outlook has a worked in email scheduler yet you don't have a 'local' choice to postpone the conveyance of email messages inside Gmail or Google Inbox. Email Studio is a Gmail add-on that won't just assist you with planning email messages inside Gmail yet you can likewise send repeating messages. Appreciate a free suite of highlights - including Mail, Calendar, People, Tasks, Office Online, and that's only the tip of the iceberg - intended to assist you with being increasingly beneficial, all from your inbox. Meet Outlook for Android, the application that helps a great many clients associate all their email records, schedules and documents in one advantageous spot.

Published By:

Blue Eyes Intelligence Engineering \& Sciences Publication

(C) Cobvriaht: All riahts reserved. 
Recently overhauled, Outlook for Android lets you accomplish more from one ground-breaking inbox. It tends to be utilized as an independent application, or can work with Microsoft Exchange Server and Microsoft SharePoint Server for different clients in an association, for example, shared letter boxes and schedules, Exchange open envelopes, SharePoint records, and meeting plans.

Important fields of Outlook.

Your Name: give your name right now;

- E-mail address: type in your email address email@domain.com for instance;

- Account Type: select whether you need to utilize the IMAP or the POP3 convention. We prescribe that you utilize the IMAP convention since it keeps your messages on the server and it's harder to lose data;

- Incoming mail server: the server for approaching sends ought to be the mail subdomain of your area name mail.yourdomain.com for instance;

- Outgoing mail server: once more, use mail.yourdomain.com as you entered for the approaching server;

- User name: the username is your full email address. It will be utilized for both approaching and active associations;

- Password: enter the secret word for your email account In the Spam isolate apparatus all the suspicious messages related with the present space are put away. It contains the messages that are for all time obstructed by the counter spam framework. The messages' pursuit depends on the Subject, Sender or Recipient esteems. The messages can be erased or discharged. On the off chance that they are discharged they will show up in the beneficiary's letter box. The bunch will be prepared naturally which messages are real and will discharge comparative ones later on.

The suspicious messages that are transitory dismissed are excluded from the isolate framework. Their conveyance will be consequently retried by the sending servers.

There was a postponement while the conveyance of a solitary message in Outlook

1. In the message, on the Options tab, in the More Options gathering, click Delay Delivery .

2. Click Message Options.

3. Under Delivery choices, select the Do not convey before check box, and afterward click the conveyance date and time that you need.

Step by step instructions to Schedule an Outgoing Email in Outlook

1. Open Outlook and snap New Email (or press Ctrl $+\mathrm{N}$ ) to communicate something specific.

2. Click the Options tab.

3. Click Delay Delivery.

4. Select the date and time you'd prefer to send the message in the Do not convey before area.

5. Click Close.

6. Press Send.

7. Open the Outbox organizer and snap to open your message.

8. Click the Options tab.

You can postpone the conveyance of an individual email message or you can utilize rules to defer the conveyance of all messages by having them held in the Outbox for a predetermined time after you click Send.

\section{GMail}

Set up a programmed email in gmail:
Boomerang for Gmail makes it straightforward for you to plan a common email. You should simply compose a message as you typically would, at that point click 'Calendar Recurring Message' from the base of the Send Later menu. From the menu, you would then be able to pick the beginning date, recurrence, day of the week to send, and end date.

1. Install Boomerang here.

2. Once the extra is stacked, reload Gmail.

3. Compose a message you need to send later.

4. Click "Send later" alongside the Send button at the top.

5. Select the time you need to send the message starting from the drop menu.

6. You can likewise set a message to be loathe as an update (or bother).

On the money click on the email, go to "Square/Bounce" and select "Bob to Sender". Affirm the activity and a phony non-conveyance email will be naturally made and put in outbox lined for sending. Last Notes: Bouncing spam could possibly get your email address off of a spammer's rundown.

\section{SYSTEM IMPLEMENTATION}

In this paper, there are 4 algorithms are used to send the emails automatically,

Step 1 : DB Scheduler algorithm - Schedule the email through from,to properties based on time to query

Step 2 : Read Excel File algorithm - Load the excel file and get the number of sheets and set the date property ad $\mathrm{mm} / \mathrm{dd}$,set the text message to send.

Step 3 : Read Properties algorithm - Read the excel file, get the cell value as date and get the email ids according to the date

Step 4: GMail Server algorithm - Set the mail authenticator (mailid,password) to login, then set the smtp port and host, then schedule it with subject,body,message to be send.

Step 5 : Through Windows Task Scheduler - Create a basic task,trigger it, schedule the message through date then running the task regularly(monthly,weekly,daily)

\section{EXECUTION - ALGORITHMS}

The DBScheduler algorithm

1. Start the scheduler

2. Read the configuration properties of setFrom,setPassword

3. sender.SendMail message setFrom to emailTo if not check the emailid

4. Schedule the time at Fixed Rate of getTimePrecision for timetoQuery

5. Check with the value of date $\mathrm{mm} / \mathrm{dd}$ same as system date.

6. Otherwise throws an exception.

7. Call the scheduler

ReadExcel File Algorithm

1. Load the excel file for $n$ number of sheets

2. Get the data iterating over each cell in a particular row.

3. Set the date as Simple Date Format (mm/dd) and getDateCellValue.

Published By:

Blue Eyes Intelligence Engineering

\& Sciences Publication

(C) Copyright: All rights reserved. 
4. Otherwise throws an exception

5. Get and Set the name,date,emailid

6. Set the text message to send.

The ReadProperties algorithm

1. Get the cell value of Date.

2. Match it with the DateFormatter

3. Get the EMailids of same date.

4. Append the list upto the end of file

5. Check with the properties of

imetoquery,setFrom,setPassword,mailTo

6. Otherwise throws an exception

GMailServer Algorithm

1. Import the mail authenticator in java

2. Set the mail host as smtp.gmail.com

3. Set the mail id and password

4. Set the properties of smtp.host,smtp.port

5. Do the sendMail function with parameters of

subject,body,sender,recipients

6. Otherwise throws an exception

Undertaking TASK SCHEDULER

The Windows Task Scheduler can consequently send email at a particular time or because of a particular occasion, yet its incorporated email include won't work very well for most clients.

Rather than utilizing the Task Scheduler's email highlight to send messages, you can utilize the Send Email utility. It permits you to develop a solitary line order that validates with a SMTP server and sends an email.

The Problem With The Task Scheduler's Email Function, When we concealed setting your PC to send you email warnings when anybody signs in, we found that the implicit email highlight had a few issues.

While you can enter any SMTP server you like, the Task Scheduler doesn't bolster validation, so you can't give a username and secret word to your SMTP server. The sort of SMTP server most clients approach (for instance, Gmail's SMTP server, or a SMTP server gave by your Internet specialist co-op) requires confirmation, so it can only with significant effort be utilized from the Task Scheduler.

In case you're running a SMTP server on your nearby PC, the Task Scheduler's email capacity might be valuable to you. Nonetheless, the normal client will require another device that is the place Send Email comes in.

To make an assignment that naturally sends an email at a particular time or an errand that sends an email in light of a particular occasion. In the Program/content box, utilize the Browse fasten and explore to the SendEmail.exe record on your PC.

Steps:

1. Open up Windows Task scheduler by going to Start->Programs->Accessories-> System Tools-> Task Scheduler. Snap to make a fundamental undertaking.

2. This will walk you through the undertaking booking wizard, where you can allot any schedule plan you'd like for these messages to get sent.

3. On the following screen, select "Start a Program" and afterward you'll see the screen where you have to set up the undertaking. This is the place you'll enter the way for your SendEmail executable and the parameters.
Finally, the algorithms are implemented by Eclipse IDE using java and executed successfully with a record of excel file more than 2000 records.

\section{RESULTS}

The source code was written in Java and executed in Eclipse IDE. Use any GMail id with less secure connectivity. Then the source code was created as a JAR File with J2SE Environment, then entirely code it as Batch File run it on any Server System with 24 hours login system,set the scheduled timer in windows task scheduler and to save the excel files in Windows32 folder then only it won't be change to anyone.

Scheduler Started......

sender.sendMail("Subject","Hi, \n\n Wishing you daily loaded with chuckling and joy and a year that brings you much achievement. $\backslash n \backslash n$ It appears to be such an extraordinary day to state we feel so fortunate that you came our direction! Cheerful Birthday to you! Make it excellent. In $\backslash n$ Regards, In Geetha " ,Constants.setFrom,Constants.emailTO);

"Email Sent Succesfully...";

otherwise

Check your mailids.....

/ / The message has sent to you all mailids which was linked by excel sheet.

Every day the time should be allotted, during that time the task scheduler linking with the excel sheet those who are birthday on the day. It will send a birthday message to all.

\section{CONCLUSION}

In this paper, scheduler logic will follow to read a data from excel database and used an authenticated email with less secure of SMTP properties that should match with system date. Then, Using Task Scheduler of creating a basic task with a batch file it will send an email automatically. Using any IDE of supports maven properties and setting up a database of scheduler logic was used and batch file of Jar File was created that must be fed into the task scheduler of source link. Finally, Based on System's Date(mm/dd) get the data from excel database and the task of sending emails to be send appropriate users automatically.

In Future, it will be used in automatic SMS to send the messages to the recipients like Birthday wishes, New Year Wishes, Alert Messages instead of using any app (apk) and so on.

\section{REFERENCES}

1. https://en.wikipedia.org/wiki/Microsoft_Outlook

2. https://www.siteground.com/tutorials/email/microsoft-outlook/

3. https://www.tutorialspoint.com/java/java_sending_email.htm

4. https://www.java4s.com/core-java/send-java-email-in-specific-time-int erval-automatically-dynamically/

5. http://www.tutorialspoint.com/java/java_sending_email.htm

6. https://javabeat.net/sending-mail-from-java/

7. https://www.codeproject.com/Questions/376689/is-it-possible-to-sendutomatic-mail-from-java

8. https://www.developer.com/java/article.php/3866141/Use-JavaMail-to -Automate-Email-Distribution.htm.

Published By:

Blue Eyes Intelligence Engineering

\& Sciences Publication

(C) Cobvriaht: All riahts reserved. 
9. https://stackoverflow.com/questions/12421288/how-to-send-email-aut omatically-at-particular-time-of-day-in-java

10. https://docs.aws.amazon.com/lambda/latest/dg/java-create-jar-pkg-mav en-and-eclipse.html

\section{AUTHORS PROFILE}

P. Geetha, was born in 1983, in Perambalur District,Tamil Nadu, India. She is a part time research scholar of Anna University. She received her B.Tech (IT) from Madras University and M.E (CSE) from Anna University, India in 2004 and 2008 respectively. She is working as an Assistant Professor for the past 15 years from June 2004 to March 2020. Her areas of interest are Big Data Analytics, Cloud Computing, Parallel Programming and Web technologies. She published more than 15 National Journals and 5 International Journals with Scopus , Elsevier-SSRN and IEEE journal.

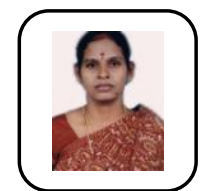

M.Thamizharasi, was born in Nagapattinam District, Tamil Nadu, India.She received her B.E(CSE),M.Tech (IT) from Anna University India in 2005 and 2010 respectively. She is working as a assistant professor for past 10 years. Her areas of interest in Theory of Compiler Design. Computation, Cloud Computing, Operating System and

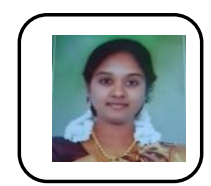

R. Reni Hena Helan, was born in Chennai, Tamil Nadu, India. She received her B.E(CSE) from Anna University, India in 2010 and M.Tech (CSE) from SRM University, India 2014 respectively. She is working as an Assistant Professor for past 5 years. Her areas of interest are Cloud Computing, Operating Systems and Big Data Analytics.

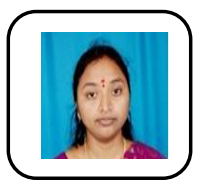

G.Abirami, was born in Madurai, Tamil Nadu, India. She received her B.E(CSE) from Madurai Kamaraj University, India in 2004 and M.E (CSE) from Hindustan University, India 2012 respectively. She is working as an Assistant Professor for past 8 years. Her areas of interest are Cloud Computing, Operating Systems and Networking.

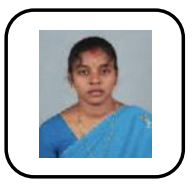

Dr G. Kalaiarasi has received her B.Tech., degree in Information Technology in the year 2004 from Srinivasa Institute of Engineering \& Technology affiliated to Madras University. She has completed M.E., in Computer Science \& Engineering in the year 2008 from Dhanalakshmi Srinivasan Engineering College which is affiliated to Anna University. She is completed her Ph.D in Information \& Communication Engineering, Anna University in the year 2019, Chennai. Her research areas are Image Processing, Image Retrieval, and Data Mining. (Based on document published on 2 June 2014).

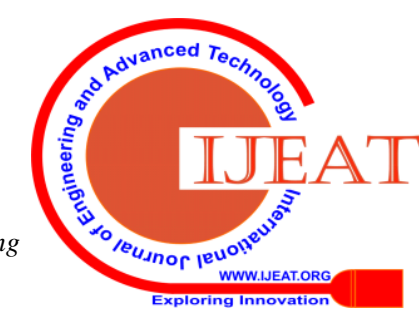

